Article

\title{
A Rule-Based Energy Management Strategy for a Plug-in Hybrid School Bus Based on a Controller Area Network Bus
}

\section{Jiankun Peng ${ }^{1}$, Hao Fan ${ }^{1}$, Hongwen He ${ }^{1,2, *}$ and Deng Pan ${ }^{1}$}

1 National Engineering Laboratory for Electric Vehicles, Beijing Institute of Technology, Beijing 100081, China; E-Mails: pengjk87@gmail.com (J.P.); haofanbit@163.com (H.F.); hdpandeng@163.com (D.P.)

2 Collaborative Innovation Center of Electric Vehicles in Beijing, Beijing Institute of Technology, Beijing 100081, China

* Author to whom correspondence should be addressed; E-Mail: hwhebit@bit.edu.cn; Tel./Fax: +86-10-6891-4842.

Academic Editor: Joeri Van Mierlo

Received: 9 March 2015 / Accepted: 25 May 2015 / Published: 1 June 2015

\begin{abstract}
This paper presents a rule-based energy management strategy for a plug-in hybrid school bus (PHSB). In order to verify the effectiveness and rationality of the proposed energy management strategy, the powertrain and control models were built with MATLAB/Simulink. The PHSB powertrain model includes an engine model, ISG (integrated started and generator) model, drive motor model, power battery packs model, driver model, and vehicle longitudinal dynamics model. To evaluate the controller area network (CAN) bus performance features such as the bus load, signal hysteresis, and to verify the reliability and real-time performance of the CAN bus multi-node control method, a co-simulation platform was built with CANoe and MATLAB/Simulink. The co-simulation results show that the control strategy can meet the requirements of the PHSB's dynamic performance. Meanwhile, the charge-depleting mode (CD) and charge-sustaining mode (CS) can switch between each other and maintain a state-of-charge (SoC) of around 30\%, indicating that the energy management strategy effectively extends the working period of the CD mode and improves the fuel economy further. The energy consumption per $100 \mathrm{~km}$ includes $13.7 \mathrm{~L}$ diesel and $10.5 \mathrm{~kW} \cdot \mathrm{h}$ electricity with an initial $\mathrm{SoC}$ of $75 \%$. The CANoe simulation results show that the bus communication performs well without error frames.
\end{abstract}


Keywords: plug-in hybrid school bus; energy management strategy; CANoe; co-simulation

\section{Introduction}

In recent years, as environmental and energy shortage problems have become increasingly serious, new energy vehicles have becomes the development trend of future vehicles. Since the current battery energy storage technology is in a bottleneck period, taking into account the energy savings and long-distance travel requirements, plug-in hybrid vehicles are currently one of best solutions for the new energy vehicle industry.

The energy of a plug-in hybrid system comes from the power battery packs and fuel, so an energy management strategy is needed to solve the multi-energy coupling problem. The power distribution among different power components is also more complex than in traditional hybrid systems, while the energy management strategy also has a significant impact on the vehicle performance [1-4]. According to the performance design requirements, the energy management strategy is used to distribute the desire drive torque or power to make the power components work in their most efficient area [5]. Energy management strategies can usually be divided into four kinds of strategy: rule-based, intelligent, instantaneous optimal energy and global optimal.

$\mathrm{Wu}$ and Boriboonsomsin presented a strategy that takes into account a priori knowledge of vehicle location, roadway characteristics and real-time traffic conditions to generate a synthesized velocity trajectory for the trip. The synthesized velocity trajectory is used to determine the battery's charge-depleting control that is formulated as a mixed-integer linear programming problem to minimize the total trip fuel consumption [6]. Jiang and Fei proposed an on-road PHEV energy management cyber-physical system (CPS) with 2-level hierarchical optimizations to minimize the fuel consumption of a trip [7]. Yu and Kuang presented a strategy that improves the fuel economy of power-split powertrain systems by optimizing the power demand distribution between the mechanical and electrical paths [8]. Zhang and Yang presented an energy management strategy with two power parameters which includes the power thresholds for determining the engine start time and the battery power optimum thresholds when the engine is working [9]. Lee and Kim studied an optimal engine-generator operating line for a plug-in hybrid electric bus (PHEB) to minimize the fuel consumption [10]. He and Chowdhury presented an innovative adaptive equivalent consumption minimization strategy for a power-split PHEV with predictive traffic information [11]. Zhang and Vahidi studied an energy management strategy for a PHEV, which is based on dynamic programming (DP) with full knowledge of future driving conditions [12].

An intelligent management strategy must acquire expert knowledge about the controlled object in advance. Although the target of an instantaneous optimal energy management strategy is optimal at any time, the system can't achieve the global optimum, and due to the large amount of computation, it's difficult to achieve real-time control. The global optimal energy management strategy can only aim at a particular driving cycle. Therefore, rule-based energy management control strategies have been widely used in practical PHEV energy management systems due to the fact the algorithms are easy to implement, and the control system has good real-time performance. 
Controller Area Network (CAN) is a serial data communication bus that can process the data exchange among numerous control and test devices in modern vehicles. Thye CAN bus has been widely used in electric vehicle control systems, due to its advantages such as good real-time performance, high reliability, quick communications rate, simple structure, good interoperability, high flexibility and so on [13].

An energy management strategy can be applied in a real vehicle by downloading it into a real vehicle controller, which is a part of the CAN communication system. Therefore, rational development of an energy management strategy needs consider the application effect of the CAN bus. Combining the simulation model of the energy management strategy and that of the CAN bus, a professional bus simulation tool is used to analyze and evaluate the co-simulation results. Then, whether the system model is accurate and whether the bus protocol can meet the design requirements can be confirmed. This work will lay the foundation for the subsequent development of the controller and reduce the development cycle and costs [14].

\section{Powertrain Architecture of PHSB}

In this paper, a series-parallel powertrain architecture is used in the PHSB, specifically shown in Figure 1, where the engine and ISG motor are mechanically integrated; the ISG motor is connected to the main drive motor through a clutch. The main parameters of the PHSB are listed in Table 1.

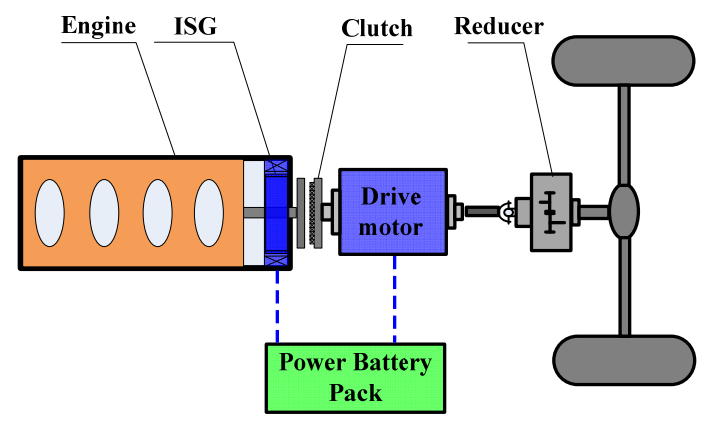

Figure 1. Powertrain architecture.

Table 1. Main parameters of the bus.

\begin{tabular}{cccc}
\hline Parameters & Values & Parameters & Values \\
\hline Unladen weight & $10,300 \mathrm{~kg}$ & Full load weight & $13,100 \mathrm{~kg}$ \\
Windward area & $7.5 \mathrm{~m}^{2}$ & Air drag coefficient & 0.65 \\
Tire rolling radius & $0.464 \mathrm{~m}$ & Final ratio & 5.33 \\
Battery capacity & $72 \mathrm{Ah}$ & Main drive motor power & $60 \mathrm{kw} / 148 \mathrm{kw}$ \\
Engine power & $147 \mathrm{kw}$ & ISG motor power & $45 \mathrm{kw} / 60 \mathrm{kw}$ \\
\hline
\end{tabular}

It can be seen from the powertrain architecture that by engaging or disengaging the clutch control and changing each power component state, seven work modes and their corresponding energy consumption modes can be achieved, as listed in Table 2. 
Table 2. PHSB work and energy consumption modes.

\begin{tabular}{cccccc}
\hline $\begin{array}{c}\text { Energy consumption } \\
\text { mode }\end{array}$ & $\begin{array}{c}\text { Clutch } \\
\text { state }\end{array}$ & $\begin{array}{c}\text { Engine } \\
\text { state }\end{array}$ & $\begin{array}{c}\text { ISG } \\
\text { state }\end{array}$ & $\begin{array}{c}\text { Drive motor } \\
\text { state }\end{array}$ & Powtrain work mode \\
\hline EV & off & off & off & Work forward & Pure electric \\
CD \& CS & off & off & off & Work backward & Low velocity regenerative brake \\
CS & off & on & on & Work forward & Series hybrid \\
CD \& CS & on & off & off & Work backward & High velocity regenerative brake \\
CD \& CS & on & on & off & off & Engine direct drive \\
CS & on & on & on & off & Engine direct drive and charge \\
CD & on & on & off & Work forward & Parallel hybrid \\
\hline
\end{tabular}

According to the power flow direction, the series hybrid mode can be divided into three sub-modes, namely APU direct drive mode, APU direct drive with additional power to charge the batteries mode and APU drive together with batteries. The clutch work states are decided by the vehicle velocity threshold. We note that in particular the clutch won't disengage during the high velocity regenerative brake mode, because the parking brake generally is not used in this mode, in order to reduce the number of clutch switches and extend the life of the clutch and the transmission, the clutch remains in an engaged status.

\section{Model of PHSB}

There are two modeling methods for hybrid systems which are forward and backward modeling. As the forward modeling method contains the driver model which can compare target velocity with actual feedback velocity to realize a closed-loop simulation, and consequently the flow of energy and control information are consistent with those of a real vehicle, therefore, the forward modeling method was used in this paper, where various powertrain component models were built based on MATLAB/Simulink, and the accuracy of the power system model was verified by using the Chinese typical city driving cycle.

\subsection{Driver Model}

The accelerator or brake pedals of the driver model are adjusted by comparing the actual velocity feedback and the target velocity, then the drive or brake torque can be determined and the following velocity can be realized in real-time. Usually a PI controller is used to simulate the driver operation, and the driver's PI controller is shown by Equations (1)-(3) below:

$$
\begin{gathered}
v_{e}=v_{\text {ref }}-v_{f} \\
A_{c c}=\frac{1}{A}\left(k_{p} \times v_{e}+\lambda_{i} k_{i} \int_{0}^{t} v_{e} d t\right) \\
\lambda_{i}= \begin{cases}0 & \left|k_{i} \int_{0}^{t} v_{e} d t\right|>A \\
1 & \left|k_{i} \int_{0}^{t} v_{e} d t\right| \leq A\end{cases}
\end{gathered}
$$

where $v_{\text {ref }}$ is target velocity, $v_{\mathrm{f}}$ is the actual velocity feedback, $v_{\mathrm{e}}$ is the deviation from the target velocity and the actual velocity feedback, $A_{\mathrm{cc}}$ is the depth of the accelerator or brake pedal which is normalized 
to $[-1,1]$, where $[0,1]$ is the opening of the accelerator pedal and $[-1,0)$ is the opening of the brake pedal, $A$ is the full-scale value of the pedal, $k_{\mathrm{p}}$ is the ratio adjustment factor, $k_{\mathrm{i}}$ is the integral adjustment factor, $\lambda_{\mathrm{i}}$ is the integral anti-saturation factor.

Drive or brake demand torque can be obtained by the following equation:

$$
T_{d}=A_{c c} \times T_{t o t}
$$

where $T_{\mathrm{d}}$ is the demand torque, $T_{\mathrm{d}} \geq 0$ means drive torque, $T_{\mathrm{d}}<0$ means brake torque, $T_{\text {tot }}$ is the maximum or optimum torque output at the current speed, which is a function of the driveshaft speed.

\subsection{Engine Model}

The engine is a complex nonlinear dynamic model, so considering the simplicity of the model and the real-time simulation, the steady-state experimental data modeling method is used to simulate the engine and its controller. The steady-state fuel consumption rate is given by Equation (5) below:

$$
m_{f}=\frac{T_{e} n_{e} f_{e}\left(T_{e}, n_{e}\right)}{3.6 \times 10^{6}}
$$

where $m_{\mathrm{f}}$ is fuel consumption, $T_{\mathrm{e}}$ is the engine output torque, $n_{\mathrm{e}}$ is the engine speed, $f_{\mathrm{e}}\left(T_{\mathrm{e}}, n_{\mathrm{e}}\right)$ is the engine fuel consumption rate, which is a function of the engine torque and speed that is measured by engine bench experiments.

The engine efficiency is given by Equation (6):

$$
\eta_{e}\left(T_{e}, n_{e}\right)=\frac{T_{e} n_{e}}{m_{f} Q_{l h v}} \times 100 \%
$$

where $Q_{\mathrm{lhv}}$ is the fuel low calorific value.

The engine fuel consumption curve and engine efficiency MAPs are shown in Figure 2. In this figure, BSFC means the brake specific fuel consumption.

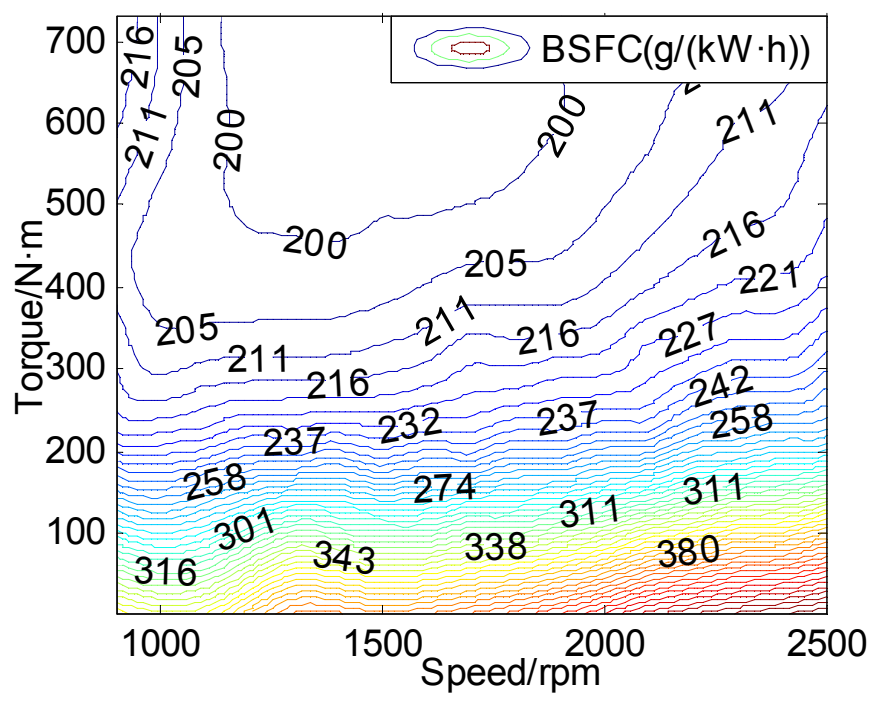

Figure 2. Brake specific fuel consumption. 
Engine fuel consumption is calculated by the following equation:

$$
\left\{\begin{array}{l}
L_{e}=\frac{m_{e}}{\rho_{e}} \\
m_{e}=\int_{0}^{t} m_{f} d t
\end{array}\right.
$$

where $m_{\mathrm{e}}$ is the fuel consumption quality, $L_{\mathrm{e}}$ is the fuel consumption volume, $\rho_{\mathrm{e}}$ is the fuel density.

According to the demand torque and speed, the engine model outputs the available engine output torque, and calculates the corresponding fuel consumption based on the above equations.

\subsection{Drive Motor and ISG Motor Models}

The drive motor and ISG motor work in the first quadrant when in a drive state, brake and power generation in the fourth quadrant, and the same quasi-steady state model method is used to simulate the motors and controllers. The quasi-steady-state equations are expressed as follows:

$$
\begin{gathered}
P_{m}= \begin{cases}\frac{T_{m} n_{m}}{\eta_{m}\left(T_{m}, n_{m}\right)} & T_{m} \geq 0 \\
T_{m} n_{m} \eta_{m}\left(T_{m}, n_{m}\right) & T_{m}<0\end{cases} \\
P_{g}= \begin{cases}T_{g} n_{g} \eta_{g}\left(T_{g}, n_{g}\right) & T_{g} \geq 0 \\
\frac{T_{g} n_{g}}{\eta_{g}\left(T_{g}, n_{g}\right)} & T_{g}<0\end{cases}
\end{gathered}
$$

where $n_{\mathrm{m}}, n_{\mathrm{g}}$ are the drive motor and ISG motor speed, respectively, $\eta_{\mathrm{m}}, \eta_{\mathrm{g}}$ are the drive motor and the ISG motor efficiency, respectively. $T_{\mathrm{m}} \geq 0$ and $T_{\mathrm{g}}<0$ represents the drive torque, $T_{\mathrm{m}}<0$ and $T_{\mathrm{g}} \geq 0$ represents brake and power generation torque. The efficiency MAP curves of the drive motor and ISG motor are shown in Figure 3.

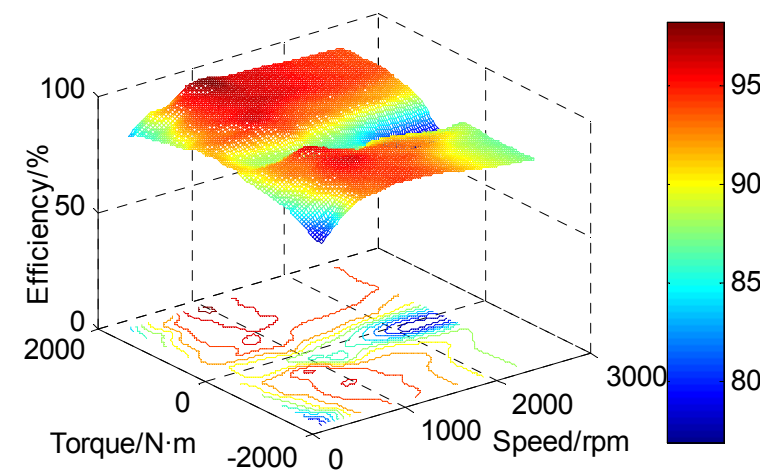

(a)

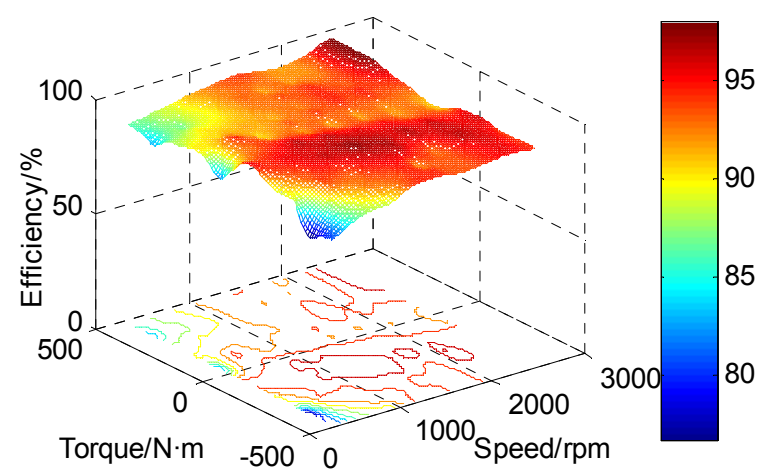

(b)

Figure 3. The efficiency MAP curves of drive motor and ISG motor: (a) Drive motor efficiency (b) ISG motor efficiency. 


\subsection{Power Battery Model}

Because the $R_{\text {int }}$ model has fewer parameters, its open circuit voltage and internal resistance can be tested by experiment, so it has been widely used in the dynamic performance simulation of electric vehicles. The power battery $R$ int model is shown in Figure 4.

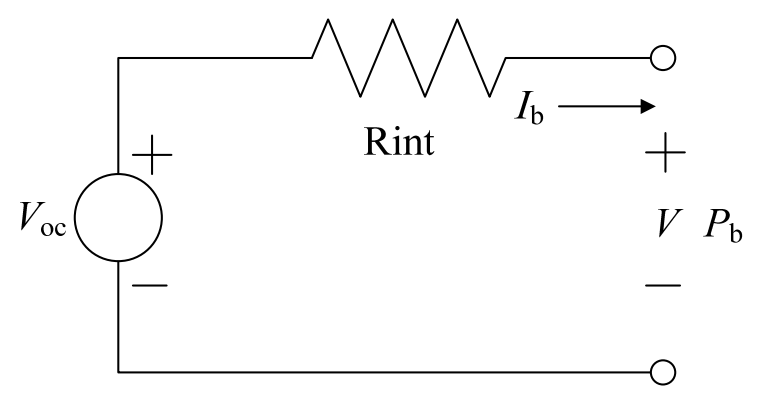

Figure 4. Power battery $R_{\text {int }}$ model.

As shown in the Figure $4, V_{\mathrm{oc}}$ is the open circuit voltage, $R_{\text {int }}$ is the battery internal resistance, $I_{\mathrm{b}}$ is the circuit current, $V$ is the load voltage, $P_{\mathrm{b}}$ is the load power, and power calculation equations are as follows:

$$
\left\{\begin{array}{l}
P_{b}=V_{o c} I_{b}-I_{b}^{2} R_{\mathrm{int}} \\
V_{o c}=I_{b} R_{\mathrm{int}}+V
\end{array}\right.
$$

The battery current $I_{\mathrm{b}}$ can be obtained from Equation (10) as follows:

$$
I_{b}=\frac{V_{o c}-\sqrt{V_{o c}{ }^{2}-4 R_{\mathrm{int}} P_{b}}}{2 R_{\mathrm{int}}}
$$

where $V_{\mathrm{oc}}$ and $R_{\text {int }}$ are the functions of battery SoC and temperature, both of which can be measured by experiment. $R_{\text {int }}$ can be expressed as:

$$
R_{\text {int }}= \begin{cases}R_{\text {dis }} & P_{b} \geq 0 \\ R_{\text {chg }} & P_{b}<0\end{cases}
$$

where $R_{\text {chg }}, R_{\text {dis }}$ are the charging and discharging resistors, respectively.

The change of battery SoC can be expressed as:

$$
\left\{\begin{array}{l}
\Delta S o C=\frac{I_{b} \Delta t \eta_{b}}{Q_{0}} \\
\eta_{b}= \begin{cases}1.0 & P_{b} \geq 0 \\
0.9 & P_{b}<0\end{cases}
\end{array}\right.
$$

where $\Delta S o C$ is the change value of the battery $\operatorname{SoC}, \Delta t$ is the status update cycle, $\eta_{b}$ is the battery coulomb efficiency, $Q_{0}$ is the initial power battery capacity.

The energy consumption of power battery packs can be calculated by the following equation:

$$
J_{m}=\frac{1}{3.6 \times 10^{6}} \int_{0}^{t} V_{o c} I_{b} d t(14)
$$




\subsection{Vehicle Longitudinal Dynamics Model}

The driving force of the vehicle powertrain is transmitted to the tires which are the end of the power transfer, so it needs to overcome various resistances during PHSB driving. The PHSB driving force $F_{\mathrm{d}}$ in the driving process with different clutch states can be expressed as:

$$
F_{d}= \begin{cases}\frac{\left(T_{e}+T_{m}\right) i_{b}}{R_{w h}} & \text { mode }=0 \\ \frac{T_{m} i_{b}}{R_{w h}} & \text { mode }=1\end{cases}
$$

where mode $=0$ represents that the clutch is engaged, mode $=1$ represents that the clutch is disengaged, $i \mathrm{~b}$ is gear ratio of main drive axle, $R_{\mathrm{wh}}$ is the wheel radius.

The vehicle's road resistance $F_{\mathrm{f}}$ and air resistance $F_{\mathrm{w}}$ in the driving process are shown as follows:

$$
\left\{\begin{array}{l}
F_{f}=f m g \cos \alpha+m g \sin \alpha \\
F_{w}=\frac{C_{d} A}{21.15} v_{f}^{2}
\end{array}\right.
$$

where $f$ is the rolling resistance coefficient, $\alpha$ is the road slope, $m$ is the PHSB full load quality, $g$ is the gravity acceleration, $C_{\mathrm{d}}$ is the air resistance coefficient, $A$ is the windward area of the PHSB.

Thus, the feedback actual velocity $v_{\mathrm{f}}$ and the acceleration $a$ are:

$$
\begin{gathered}
v=3.6 \int_{0}^{t} a d t \\
a=\frac{F_{d}-F_{f}-F_{w}}{\delta m}
\end{gathered}
$$

where $\delta$ is the PHSB rotating quality conversion coefficient.

The acceleration and resistance consumption power when PHSB driving are shown as follows:

$$
P_{e}+P_{m}=P_{f}+P_{w}+P_{a}=\frac{v_{f}}{3600 \eta_{t}}\left(F_{f}+F_{w}+\delta m a\right)
$$

where $P_{\mathrm{e}}$ is the engine power, $P_{\mathrm{m}}$ is the drive motor power, $P_{\mathrm{f}}$ is the road resistance consumption power, $P_{\mathrm{w}}$ is the air resistance consumption power, $P_{\mathrm{a}}$ is the acceleration power.

The PHSB simulation model which is built with MATLAB/Simulink is shown in Figure 5. The Chinese typical city driving cycle is employed as the target velocity for the PHSB simulation model. 


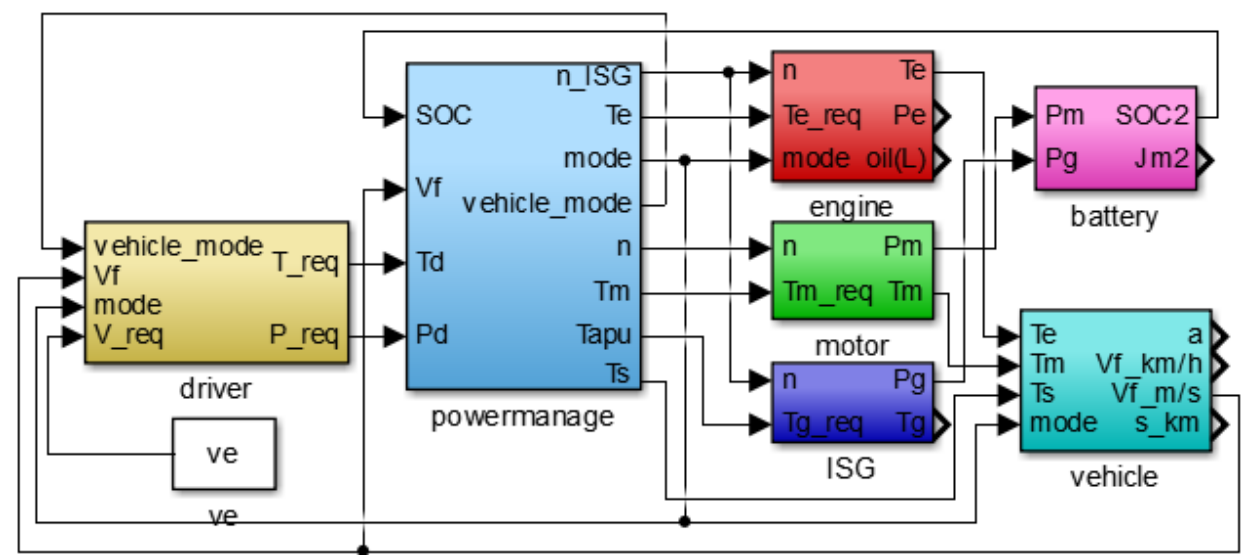

Figure 5. The simulation model of PHSB.

\section{PHSB Control Strategy}

Plug-in hybrid bus control strategy designs in general should follow the following four principles [15]:

(1) Battery energy exhaustion principle. The capacity of power battery packs for PHSB is large, so in order to maximize the battery energy use and reduce fuel consumption and emissions under the premise of ensuring the power battery packs' life, the $\mathrm{SoC}$ is requested to be consumed down to the lower limit threshold at the end of the trip, and in general the lower limit threshold is set to $30 \%$.

(2) Minimum energy circulations principle. To reduce the energy efficiency loss, the energy flow situations such as the electricity from the battery to the drive motor when APU charging battery should be avoided.

(3) Driving priority principle. The sum of each power component output power should meet the vehicle driving power requirements. Under this premise, the output power of each power component is distributed reasonably, and the optimum work points of each power component are determined, thus the vehicle power components can be ensured to working in the high efficiency area and the fuel economy can be improved.

(4) Maximum braking energy recovery principle. When the vehicle is decelerating or braking, under the premise of ensuring the braking stability for PHSB, it should recover as much braking energy from the drive motor as possible.

There are three kinds of energy consumption modes for PHSB, which are electric vehicle mode (EV), $\mathrm{CD}$ mode and CS mode. In this paper, the drive motor alone drives the vehicle during the EV mode, and all of the required energy for PHSB driving comes from the power battery packs. In the CD mode, both of the drive motor and the engine drive the PHSB, and the SoC of the power battery packs would be decreased gradually. In the CS mode, the engine provides most of the energy to drive the PHSB, and the SoC of power battery packs was maintained within an appropriate range until the PHSB stops. The energy consumption modes switching control strategy is shown in Figure 6, where SoC_CD is the switch threshold between the EV mode and the CD mode, and SoC_CS is the switch threshold between the CD mode and the CS mode, o is the margin of switching back to CD mode from CS mode. In one PHSB trip, the mode switches constantly with the change of SoC, and EV mode switches to CD mode can't be reversed unless the parking charge happens, but mode switch between CD mode and CS mode can be reversed when the SoC increases to a certain level. 


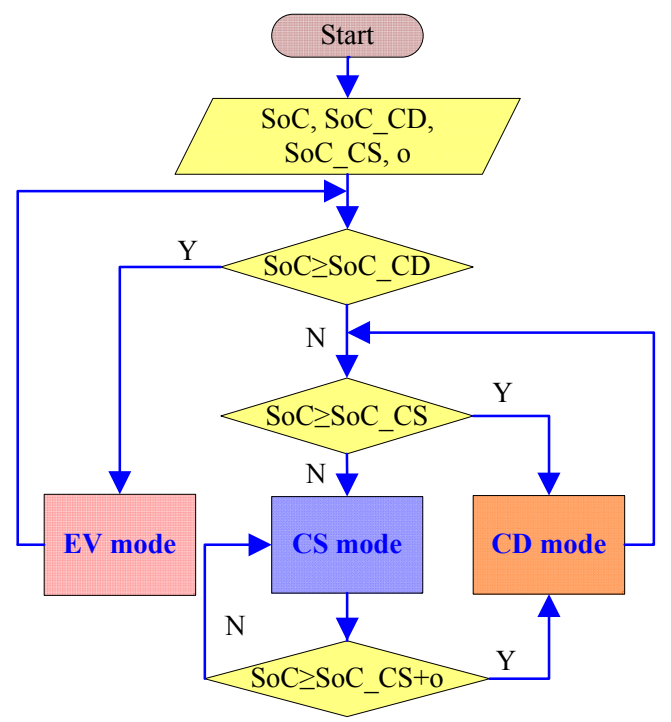

Figure 6. Mode switching control strategy.

The selection of the engine optimal work area is mainly based on the engine optimal work curve. As shown in Figure 7, the engine optimal work curve is fitted by the engine optimal work points, which correspond to the minimum fuel consumption and best fuel economy of the engine In this paper, Te_max(n) is the upper boundary of the engine optimal work area, which is the engine optimal work curve, and Te $\min (\mathrm{n})$ is the lower boundary of the engine optimal work area, which is the $230 \mathrm{gp} \cdot \mathrm{kW} \cdot \mathrm{h}$ fuel consumption contour. Therefore, the engine fuel consumption rate can be controlled below $230 \mathrm{gp} \cdot \mathrm{kW} \cdot \mathrm{h}$.

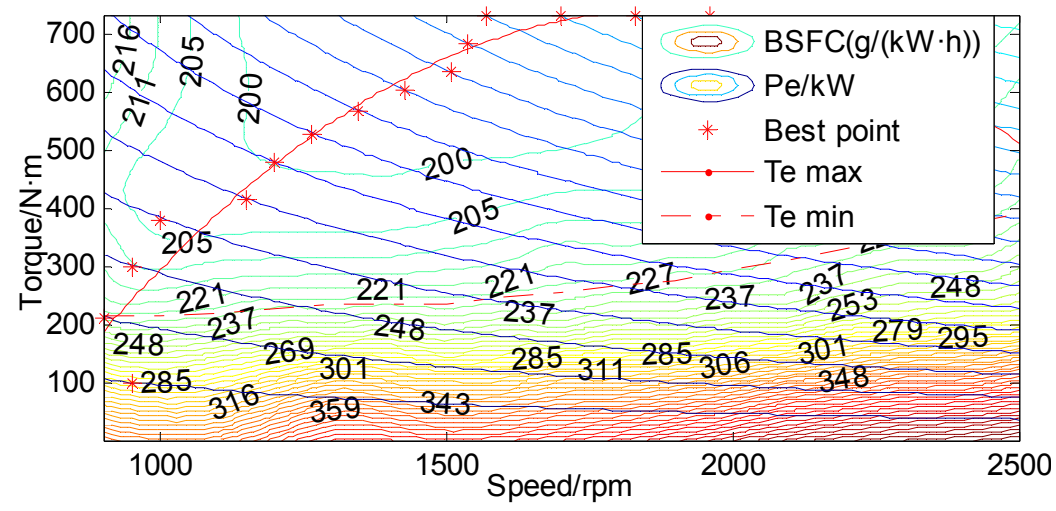

Figure 7. Engine optimal work curve.

\subsection{EV Mode}

When $\mathrm{SoC}>65 \%$, the vehicle is in the EV (equivalent to a pure electric vehicle) mode. As shown in the Figure 8, the energy is provided by the power battery packs at this time, and the driving demand is satisfied by the drive motor. In this mode, because of the higher SoC and the lower charge efficiency, regenerative braking is not performed to reduce the charge times and extend the power battery life. 


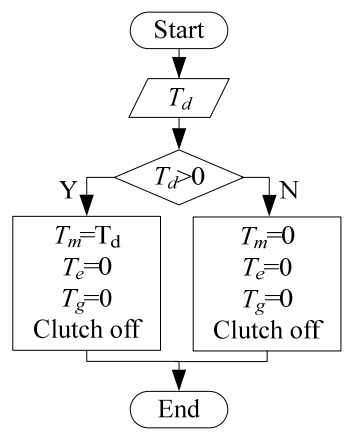

Figure 8. Energy management control strategy in EV mode.

\subsection{Mode}

When $30 \%<\mathrm{SoC}<65 \%$, it's the $\mathrm{CD}$ mode and the corresponding control strategy flow is shown in Figure 9. The PHSB is only driven by the drive motor when PHSB drives at a low speed. When the PHSB drives at a high speed, if the drive demand torque is less than the lower limit of the engine optimal work area, the engine shuts down, and the torque is provided by the drive motor; if the drive demand torque is in the engine optimal work area, the engine direct drive mode is adopted; if the drive demand torque is greater than the upper limit of the engine optimal work area, the engine and the main drive motor work jointly to meet driving demand. Regenerative braking can be employed to recover braking energy in CD mode.

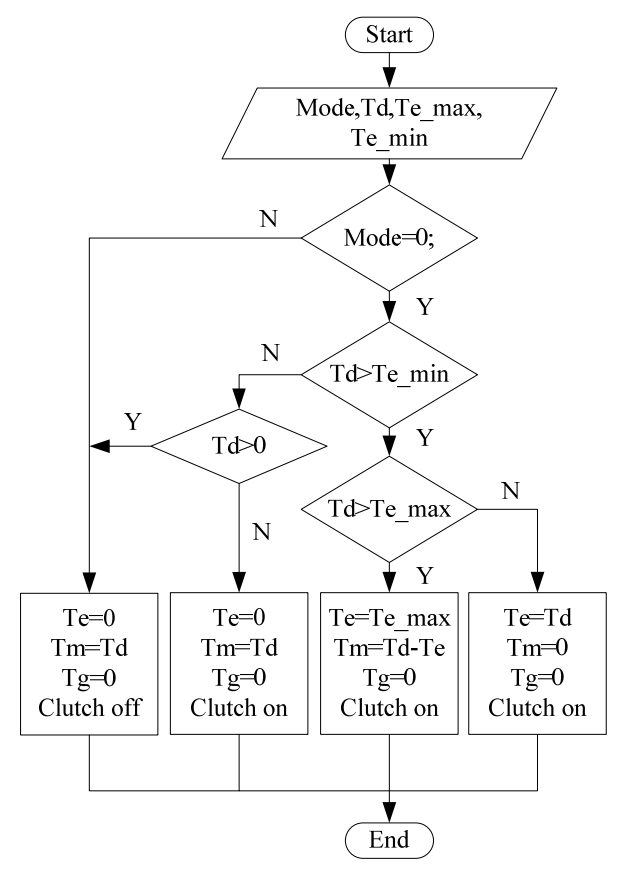

Figure 9. Energy management control strategy in CD mode.

\subsection{CS Mode}

The control strategy follow of CS mode is shown in Figure 10 as follows: when $\mathrm{SoC}<35 \%$, it is the CS mode. At this time, the control strategy needs to ensure the SoC is stabilized near $30 \%$. The series hybrid mode is adopted when the PHSB drives at a low speed, and the demand power is satisfied by the drive motor. 


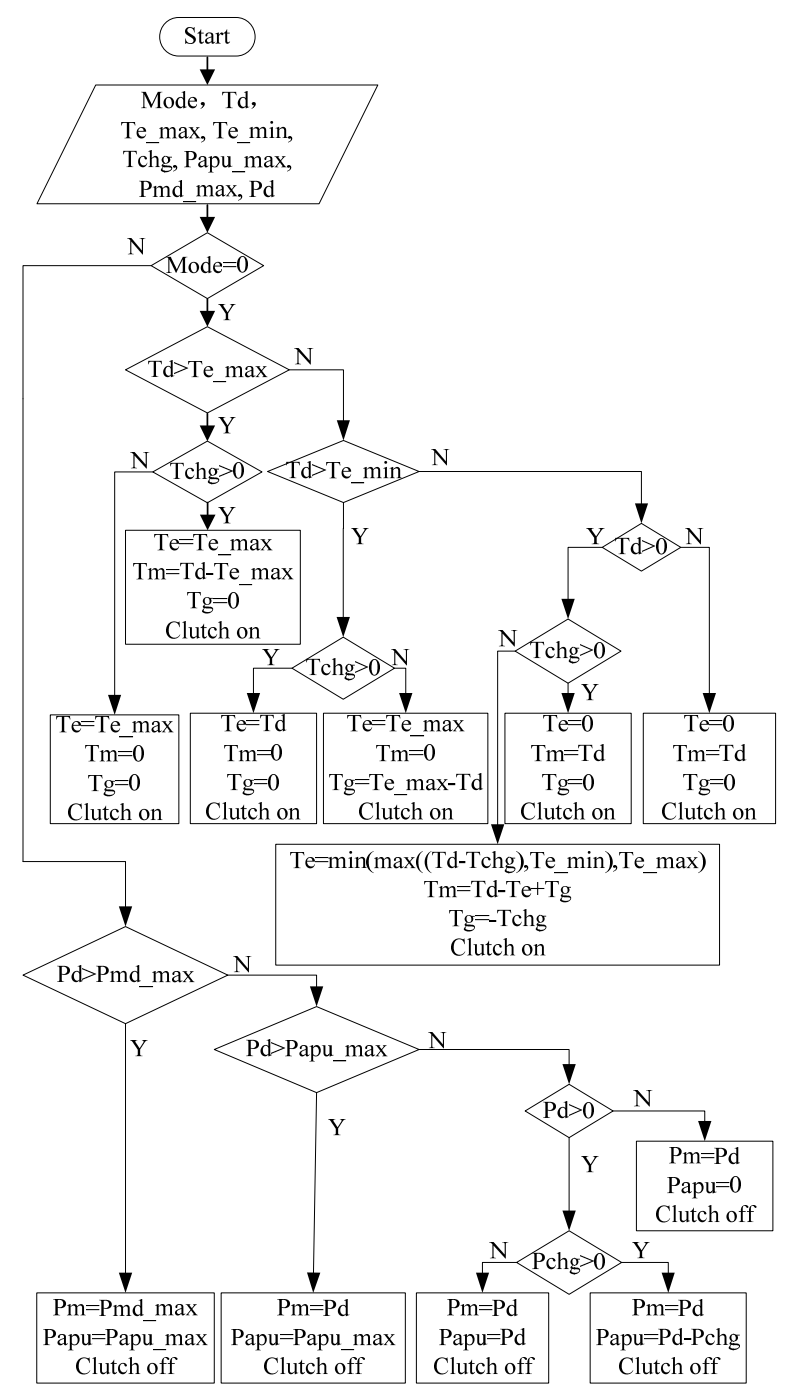

Figure 10. Energy management control strategy in CS mode.

If the power demand is greater than the APU maximum power, the APU works at the maximum power point; if the power demand is less than the APU maximum power but more than the lower limit of the APU and $30 \%<\mathrm{SoC}<31 \%$, to minimize energy circulation, the APU output power is equal to the demand power; if the demand power is less than the APU maximum power but more than the lower limit of the APU and $29 \%<\mathrm{SoC}<30 \%$, due to the power battery packs power shortage at this time, APU outputs the maximum power, meanwhile providing power to the drive motor and charging the power battery packs; if the demand power is less than the lower limit of the APU, APU works at the lower limit of the APU, it provides power to the drive motor and powers the battery packs at the same time, although it has energy circulation, it can be ensured that the engine works in optimal the work area, so the fuel consumption can be further reduced. This mode also allows regenerative braking to recover energy.

The series-parallel hybrid mode is adopted when PHSB drives at a high speed. When $30 \%<\mathrm{SoC}<31 \%$, if the drive demand torque is less than the lower limit of the engine optimal work area, the demand torque is only provided by the drive motor, and the engine shuts down; if the drive demand torque is in the engine optimal work area, the engine direct drive mode is adopted; if the drive demand torque is greater than the upper limit of the engine optimal work area, the engine and the main 
drive motor work together to meet the running demand. Regenerative braking can be employed to recover energy in this mode.

When $29 \%<$ SoC $<30 \%$, it needs to charge the power battery packs. If the drive demand torque is less than the lower limit of the engine optimal work area, the engine works in the engine optimal work area to drive the PHSB directly and start the ISG motor to charge the power battery packs; if the demand torque is in the engine optimal work area, the engine works at the upper limit of the engine optimal work area or the sum of the charge demand torque and demand torque, using the engine to drive directly and start the ISG motor to charge power battery packs; if the drive demand torque is greater than the upper limit of the engine optimal work area, the engine works atthe upper limit of the engine optimal work area to drive the bus, and the drive motor does not participate in the drive process. It also allows regenerative braking to recover energy in this mode.

\section{Co-Simulation Experiments}

CANoe is a CAN bus simulation and test software that by using the $\mathrm{CANdb}++$ database can simulate the communication protocol of the CAN bus. Although the control algorithm design and the control of CAN communication for each node can be realized in CANoe by using CAPL language, it seems jumbled and complicated for complex control algorithm and CAN communication.

MATLAB/Simulink is easy to use for developing complex control algorithms, but it lacks the capability of modeling and simulating a CAN bus. Therefore, the open interfaces of CANoe for Simulink are used to combine these two softwares for co-simulation, and the effect of the specified control strategy in CAN environments can be observed. The co-simulation detailed principle and bus topology structure are shown in Figure 11.

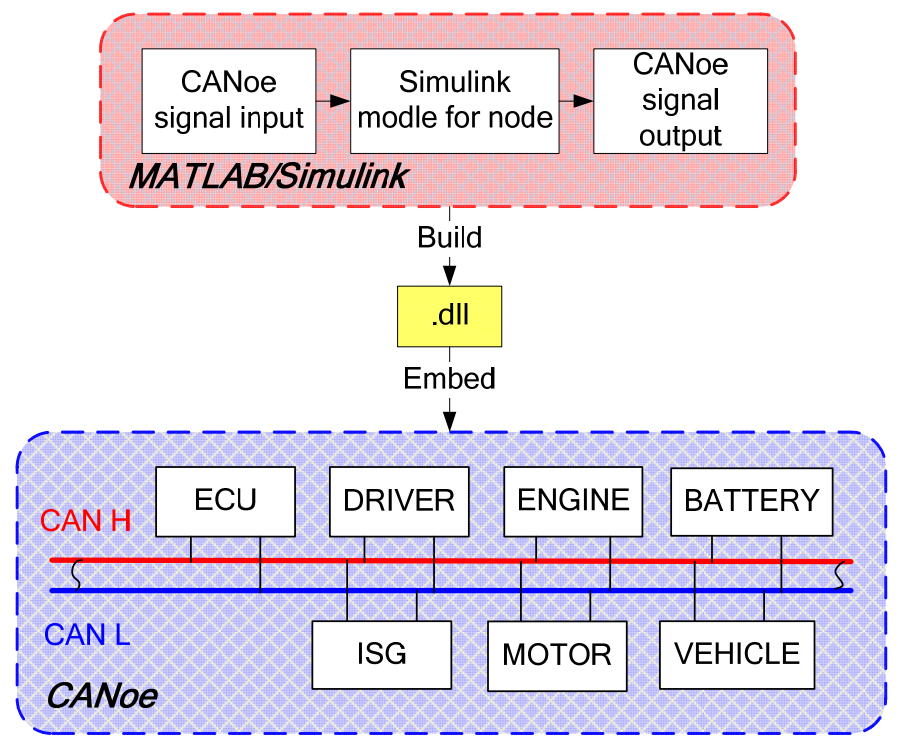

Figure 11. The co-simulation schematic of plug-in school bus.

The co-simulation is carried out by using CANoe/Simulink, through the introduction of a simulated CAN bus connection to each sub-controller and vehicle model in the CANoe environment, the CAN bus load, signal delay and other characteristic parameters for the developed control strategy can be tested. The specific development procedures are as follows: 
Firstly, the $\mathrm{CANdb}++$ database was built, then the control strategy model was made a node, and all other power components models serve as individual nodes. The signals which are needed to transfer through the CAN bus associated with the sending and receiving messages of each node, and the completed setup database file was imported into a CANoe development panel. The signals of each node are as shown in Figure 12.

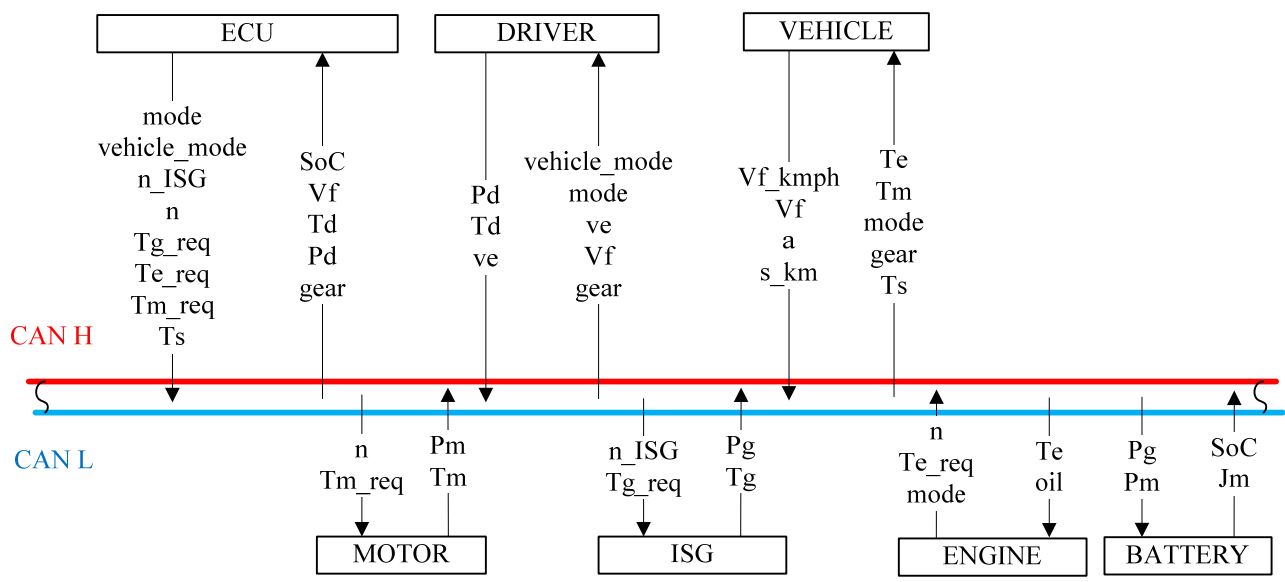

Figure 12. Nodes send and receive signals schematic diagram.

Then, the input and output interfaces of models in Simulink of each control node were replaced with the corresponding Simulink/CANoe module interfaces, thus the signal association were completed. The models were converted into the .dll format control code through fast code generation technology, then the .dll file is embedded into the corresponding nodes of the CANoe development panel.

Finally, we verify whether the control strategy can send and receive signals according to the actual requirements by simulating the CAN bus environment, and observe the communication evaluation indexed like CAN bus load and so on, so as to complete the test and evaluation of the PHSB energy management strategy in the simulated CAN bus environment.

\section{Simulation Results and Analysis}

To verify the effectiveness and reasonability of the energy management strategy, several simulation experiments were carried out with the CANoe software. As shown in Figure 13, the Chinese typical city driving cycle is selected as the target velocity of the driver model.

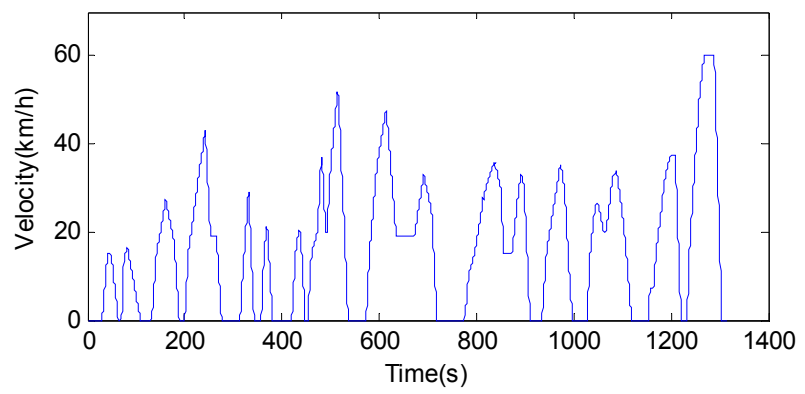

Figure 13. Chinese typical city driving cycle. 
In order to make the control strategy have a better display effect in this paper, three Chinese typical city driving cycles were run, however, wecan't fully verify the mode switching of the control strategy by running only three Chinese typical city driving cycles, therefore, to reflect the three mode switches in the whole simulation process, the initial value of power battery packs SoC is set as $85 \%$, the total capacity is reduced to $10 \mathrm{Ah}$, and the CAN bus baud rate is set as $500 \mathrm{kbs}$.

The effect of velocity following is shown in Figure 14. The actual velocity can follow the velocity of the driving cycle well, and the requirements of the vehicle dynamic performance can be met, which indicates that the vehicle control strategy is reasonable and effective.

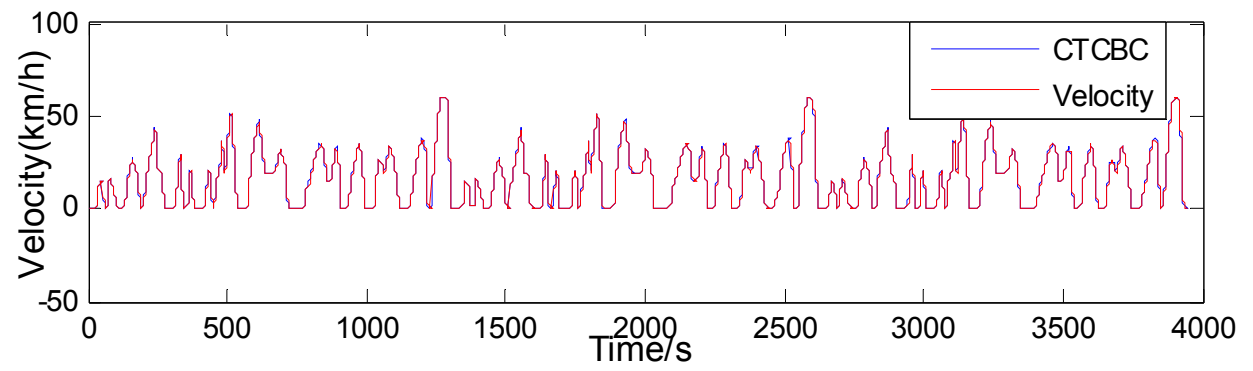

Figure 14. The velocity following curve.

Figure 15 shows the power following between the total output power and the demand power. The results indicates that negative demand power does not coincide with the total output power before $870 \mathrm{~s}$. The reason for this phenomenon is that the SoC is high in EV mode, and the designed control strategy does not allow charging and regenerative braking, so only the drive power can achieve a good follow effect. After $870 \mathrm{~s}$, the work mode was changed into the CD and CS modes gradually, then the control strategy allows ISG motor generation and brake energy recovery, so that the total output power can better follow the power demand.

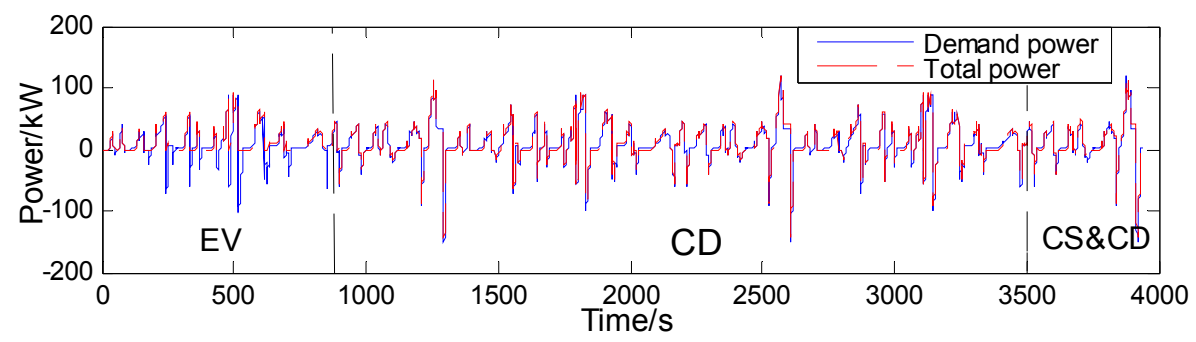

Figure 15. The power following curve.

The work torque of power components is shown in Figure 16. The engine does not work in EV mode, so the engine output torque is always 0 ; the ISG motor only works in CS mode, thus its torque is always 0 in the EV and CD modes; meanwhile in CS mode, the engine work range is larger than that in CD mode, due to the fact the engine not only provides the drive power in most stages, but also provides the generated power to the APU according to the control strategy in the CS stage, therefore, the engine output torque is greater than that in $\mathrm{CD}$ mode. 


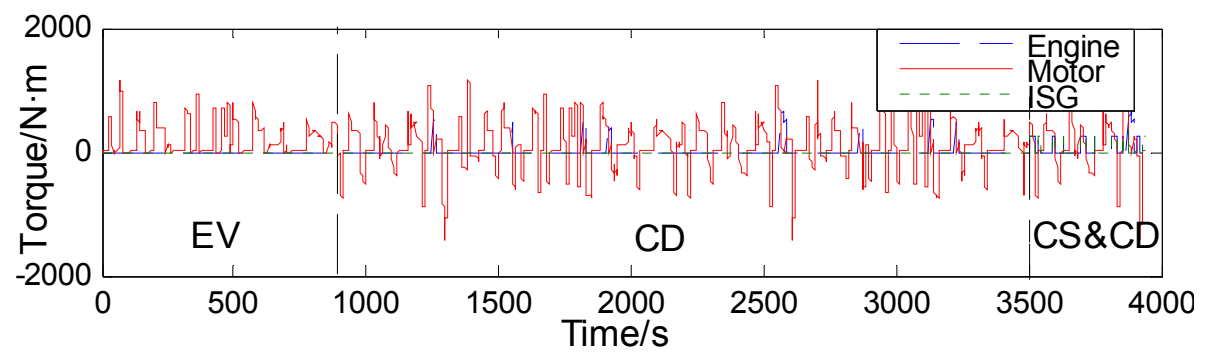

Figure 16. Power components torque contrast.

Figure 17 indicates that when the $\mathrm{SoC}$ is between $65 \%$ and $85 \%$, the bus works in EV mode, without driving charging and regenerative braking, so the SoC doesn't grow; the bus works in CD mode when the $\mathrm{SoC}$ is less than $65 \%$, since this mode allows regenerative braking, the phenomenon that the SoC is increasing appears; when the SoC is less than 30\%, the bus works in CS mode, SoC fluctuates between $29 \%$ and $31 \%$, because the SoC change leads to the CD and CS mode switching, and finally makes the SoC fluctuate around $30 \%$. It can be seen by the declining SoC slope, due to the fact the vehicle drive energy is not only from battery power, that the slope declines of SoC in CD and CS mode are slower than that in EV mode.

The energy consumption mode switch process of the control strategy is as shown in Figure 18, and modes 1, 2, 3 represent EV, CS and CD modes, respectively. Combined with Figure 17, it can be seen that, in accordance with the SoC change, switches between $\mathrm{CD}$ and EV mode can't be reversed, but the switch between CD and CS mode is reversible. This results indicates that the designed control strategy can achieve CS and CD mode switching effectively during the subsequent PHSB travel, namely extending the use time of the $\mathrm{CD}$ mode, which is consistent with the control of objectives global optimization, and this is helpful for enhancing the fuel saving potential of the rule-based energy management control strategy.

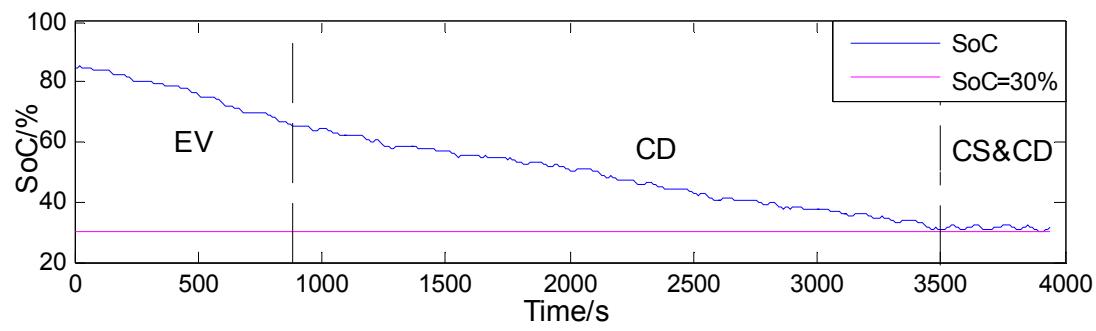

Figure 17. SoC change curve.

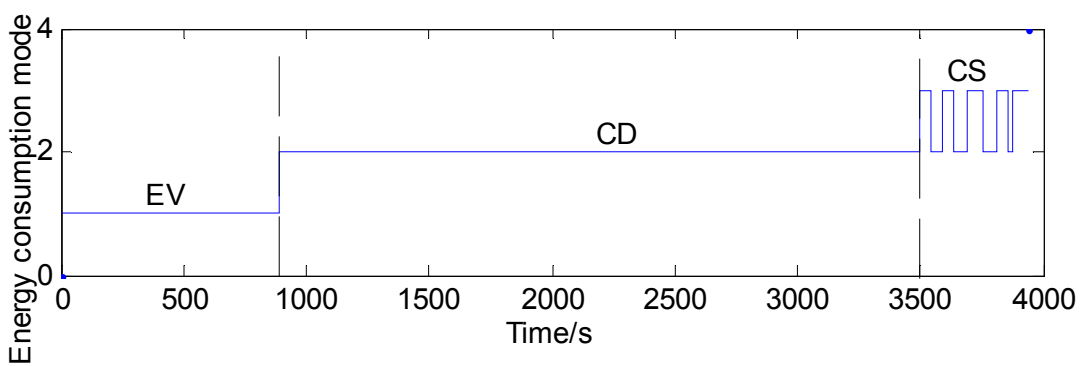

Figure 18. Energy consumption modes switch. 
Figure 19 indicates that the engine work points (blue *) are always in the engine optimal work area, proving that the designed control strategy can obtain good fuel economy performance.

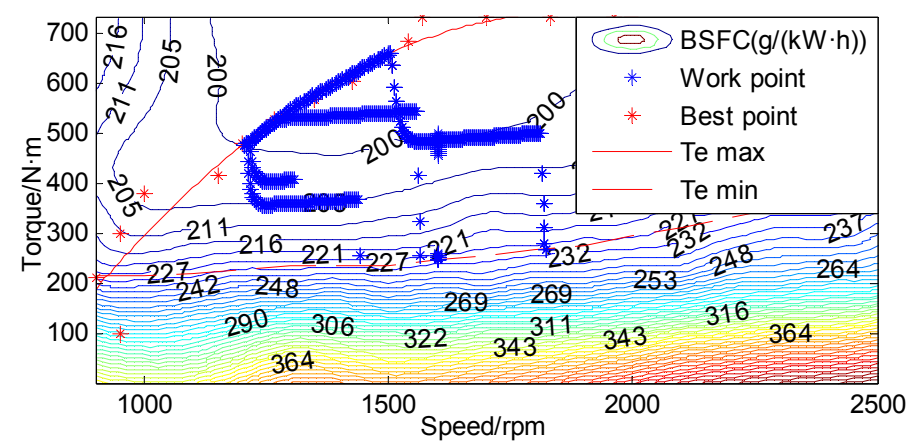

Figure 19. Engine work points.

The battery capacity is restored to $72 \mathrm{Ah}$, and the $\mathrm{SoC}$ initial value is set as $75 \%, 19$ Chinese typical city driving cycles were ran, and the resulting diesel consumption and electricity consumption are shown in Figure 20, where the diesel consumption and electricity consumption are $15.3 \mathrm{~L}$ and $10.7 \mathrm{~kW} \cdot \mathrm{h}$, which are equivalent to an energy consumption per $100 \mathrm{~km}$ of $13.7 \mathrm{~L}$ diesel consumption and $10.5 \mathrm{~kW} \cdot \mathrm{h}$ electricity consumption.

It can be seen from the above simulation results that the designed control strategy is reasonable and effective, the demand of PHSB dynamic performance can be guaranteed, meanwhile, the fuel consumption and power consumption reflect that the control strategy has good economic performance. If considering that the bus is running from the power battery fully charged state, due to the extended work hours of EV mode, the fuel saving effect will be more obvious.

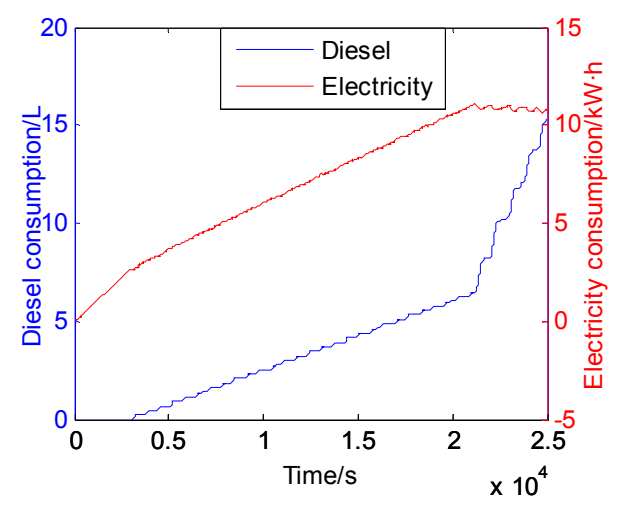

Figure 20. Diesel and electricity consumption.

In order to detect the impact of the CAN bus performance indicators such as the load factor and signal delay on the control effect, a comparative velocity simulation was carried out with Simulink and CANoe. The comparison results are as shown in Figure 21, where it can be seen that the two curves are basically the same. 


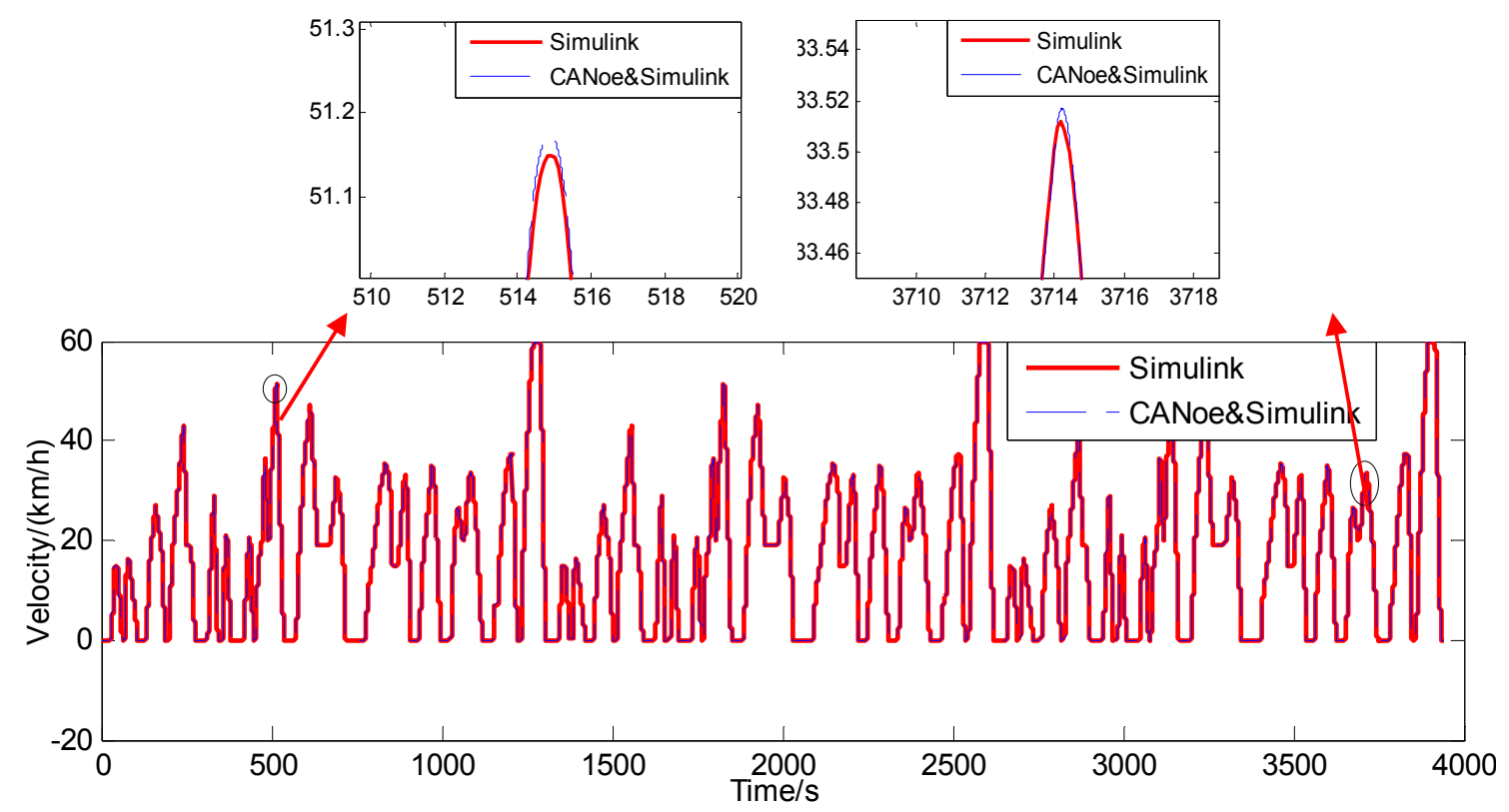

Figure 21. Velocity comparison from two kinds of simulations.

It can be found by amplifying the details that the errors of the two simulation results during the rapid changes of the driving cycle are larger than at other positions, namely around the corner of the velocity curve. The communications between the nodes in Simulink are idealized, thus it's not necessary to consider the delay response problems of the control signals. While in the CANoe environment, which adds the CAN bus simulation model, signals are transmitted at a fixed period between nodes through messages, so it can reflect the signals transmission process more truly. The power and torque of power components always change sharply at the rapid changes of the driving cycle, and the hysteresis effect of the simulation bus will enlarge the differences between the CANoe and Simulink simulation results.

For the velocity simulation results of CANoe and Simulink, 4000 sampling times' velocities were selected randomly, and the error and the correlation coefficient between the two sets of sampling data are compared. The specific relevant indicators are shown in Table 3.

Table 3. Sampling velocity comparison.

\begin{tabular}{cc}
\hline Parameter & Value \\
\hline Maximum error $(\mathrm{m} / \mathrm{s})$ & 0.1071 \\
Minimum error $(\mathrm{m} / \mathrm{s})$ & 0 \\
Error standard deviation $(\mathrm{m} / \mathrm{s})$ & 0.0316 \\
Correlation coefficient & 0.98 \\
Determination coefficient & 0.96 \\
\hline
\end{tabular}

The correlation coefficient can be used to represent the level of direct linear relationship intensity between the two sets of sample data, and the determination coefficient is the square of the correlation coefficient, which determines the close level of the comparative sample data, the correlation coefficient expression is as follows: 


$$
r_{X Y}=\frac{\sum_{i=1}^{N}\left(X_{i}-\bar{X}\right)\left(Y_{i}-\bar{Y}\right)}{\sqrt{\sum_{i=1}^{N}\left(X_{i}-\bar{X}\right)^{2}} \sqrt{\sum_{i=1}^{N}\left(Y_{i}-\bar{Y}\right)^{2}}} \quad(N=4000)
$$

where $X$ represents the samples of the CANoe simulation results, $Y$ represents the samples of the Simulink simulation results.

It can be seen from the Table 3 that there is close correlation between the two simulation results, and the impact caused by CAN communication delay is small. The evaluation parameters of CAN bus communication effect in CANoe software are shown in Figure 22, which indicates that the CAN bus load rate maximum is $27.31 \%$, less than $30 \%$, thus it won't cause a bus jam, the message delay is reasonable, the minimum interval for sending is $0 \mathrm{~ms}, 12$ frames are sent each time, consistent with number of messages, the average transmission time is $2.710 \mathrm{~s}$, and there are no error frames, no sending and receiving errors, so all the CAN communication properties meet the design requirements.

\begin{tabular}{|c|c|c|c|c|}
\hline Statistic & Current / Last & Min & Max & Avg \\
\hline$\bigoplus$ Busload $[\%]$ & 27.02 & 26.97 & 27.31 & 27.09 \\
\hline Min. Send Dist. [ms] & 0.000 & $\mathrm{n} / \mathrm{a}$ & $\mathrm{n} / \mathrm{a}$ & $\mathrm{n} / \mathrm{a}$ \\
\hline$\stackrel{i}{+} \cdot$ Bursts [total] & 1723 & $\mathrm{n} / \mathrm{a}$ & $\mathrm{n} / \mathrm{a}$ & $\mathrm{n} / \mathrm{a}$ \\
\hline$\stackrel{\dagger}{\dagger}$ Burst Time [ms] & 2. 720 & 2. 684 & 2. 816 & 2. 710 \\
\hline$\stackrel{i}{+} \cdot$ Frames per Burst & 12 & 12 & 12 & 12 \\
\hline Std. Data $[\mathrm{fr} / \mathrm{s}]$ & 1200 & 1188 & 1200 & 1199 \\
\hline Std. Data [total] & 20676 & $\mathrm{n} / \mathrm{a}$ & $\mathrm{n} / \mathrm{a}$ & $\mathrm{n} / \mathrm{a}$ \\
\hline$\stackrel{i}{+} \cdot$ Ext. Data $[\mathrm{fr} / \mathrm{s}]$ & 0 & 0 & 0 & 0 \\
\hline Ext. Data [total] & 0 & $\mathrm{n} / \mathrm{a}$ & $\mathrm{n} / \mathrm{a}$ & $\mathrm{n} / \mathrm{a}$ \\
\hline Std. Remote $[\mathrm{fr} / \mathrm{s}]$ & 0 & 0 & 0 & 0 \\
\hline †'. Std. Remote [total] & 0 & $\mathrm{n} / \mathrm{a}$ & $\mathrm{n} / \mathrm{a}$ & $\mathrm{n} / \mathrm{a}$ \\
\hline Ext. Remote $[\mathrm{fr} / \mathrm{s}]$ & 0 & 0 & 0 & 0 \\
\hline$\stackrel{\dot{\dagger}}{\dot{\dagger}}$ Ext. Remote [total] & 0 & $\mathrm{n} / \mathrm{a}$ & $\mathrm{n} / \mathrm{a}$ & $\mathrm{n} / \mathrm{a}$ \\
\hline Errorframes [fr/s] & 0 & 0 & 0 & 0 \\
\hline Errorframes [total] & 0 & $\mathrm{n} / \mathrm{a}$ & $\mathrm{n} / \mathrm{a}$ & $\mathrm{n} / \mathrm{a}$ \\
\hline †. Chip State & Simulated & $\mathrm{n} / \mathrm{a}$ & $\mathrm{n} / \mathrm{a}$ & $\mathrm{n} / \mathrm{a}$ \\
\hline Transceiver Errors & 0 & $\mathrm{n} / \mathrm{a}$ & $\mathrm{n} / \mathrm{a}$ & $\mathrm{n} / \mathrm{a}$ \\
\hline
\end{tabular}

Note: $\mathrm{n} / \mathrm{a}$ means the property parameter can't be used in the corresponding analysis.

Figure 22. The CAN communication evaluation parameters in CANoe.

\section{Conclusions}

(1) In this paper, MATLAB/Simulink software is used to build a forward simulation model for a PHSB, and a rule-based energy management strategy is developed. In order to study the response of designed control strategy in the CAN bus environment, a simulation model of a singlet topology CAN bus is built with CANoe, and every model of the PHSB simulation model in the Simulink environment is separately imported to the corresponding node of the CAN bus simulation model through automatic code generation techniques. 
(2) The Chinese typical city driving cycle is used as a target velocity, and several simulation experiments were carried out with CANoe. The simulation results show that the developed rule-based control strategy can follow well the target velocity and demand power, indicating that the developed control strategy can meet the requirements of PHSB dynamic performance. Meanwhile, it can realize CD mode and CS mode switching in the subsequent travel, and the SOC is stabilized around 30\%. The energy consumption per $100 \mathrm{~km}$ is $13.7 \mathrm{~L}$ diesel and $10.5 \mathrm{~kW} \cdot \mathrm{h}$ electricity with an initial SoC of $75 \%$, so the economy requirements of the PHSB can be guaranteed.

(3) The velocity comparison results between the Simulink/CANoe co-simulation and the Simulink individual simulation show that the correlation coefficient of the two sets of sampling velocities is 0.98 , and the determination coefficient is 0.96 , which indicates that the developed control strategy has a reasonable bus load and little delay effect. Co-simulation results shows that the bus communication is normal, there are no error frames, and each indicator of the bus communication is reasonable. The control strategy validation in the bus simulation environment shows that the developed control strategy has real-time and high reliability performance, so the study presented in this paper could lay the foundation for the hardware development of a vehicle controller.

\section{Acknowledgments}

This work was supported by the National High Technology Research and Development Program of China (2013BAG05B00) in part, the Program for New Century Excellent Talents in University (NCET-11-0785) and Beijing Institute of Technology Post Graduate Students Innovation Foundation in part. The author would also like to thank the reviewers for their corrections and helpful suggestions.

\section{Author Contributions}

Jiankun Peng and Hao Fan built the model of PHSB and performed the co-simulations, Hongwen He designed the control strategy, Deng Pan debugged the algorithm. All authors carried out data analysis, discussed the results and contributed to writing the paper.

\section{Conflicts of Interest}

The authors declare no conflict of interest.

\section{References}

1. Borhan, H.; Vahidi, A.; Phillips, A.M.; Kuang, M.L.; Kolmanovsky, I.V.; di Cairano, S. MPC-based energy management of a power-split hybrid electric vehicle. IEEE Trans. Control Syst. Technol. 2012, 20, 593-603.

2. Zhang, B.Z.; Mi, C.C.; Zhang, M.Y. Charge-depleting control strategies and fuel optimization of blended-mode plug-in hybrid electric vehicles. IEEE Trans. Veh. Technol. 2011, 60, 1516-1525.

3. Wirasingha, S.G.; Emadi, A. Classification and review of control strategies for plug-in hybrid electric vehicles. IEEE Trans. Veh. Technol. 2011, 60, 111-122. 
4. Tulpule, P.; Marano, V.; Rizzoni, G. Effects of different PHEV control strategies on vehicle performance. In Proceedings of the American Control Conference (ACC), St. Louis, MO, USA, 10-12 June 2009; pp. 3950-3955.

5. Xiao, R.X. Plug-in Hybrid Vehicle Energy Management Optimization and Auxiliary Power Component Control Research; Kunming University: Kunming, China, 2012. (In Chinese)

6. Wu, G.; Boriboonsomsin, K.; Barth, M.J. Development and evaluation of an intelligent energy-management strategy for plug-in hybrid electric vehicles. IEEE Trans. Intell. Transp. Syst. 2014, 15, 1091-1100.

7. Jiang, B.N.; Fei, Y.S. On-road PHEV Power management with hierarchical strategies in vehicular networks. In Proceedings of the IEEE Intelligent Vehicles Symposium (IV), Dearborn, MI, USA, 8-11 June 2014; pp. 1077-1084.

8. Yu, H.; Kuang, M.; McGee, R. Trip-oriented energy management control strategy for plug-in hybrid electric vehicles. In Proceedings of the 50th IEEE Conference on Decision and Control and European Control Conference (CDC-ECC), Orlando, FL, USA, 12-15 December 2011; pp. 5805-5812.

9. Zhang, M.Y.; Yang, Y.; Mi, C.C. Analytical approach for the power management of blended-mode plug-in hybrid electric vehicles. IEEE Trans. Veh. Technol. 2012, 61, 1554-1566.

10. Lee, D.H.; Kim, N.W.; Jeong, J.R.; Park, Y.I.; Cha, S.W. Component sizing and engine optimal operation line analysis for a plug-in hybrid electric transit bus. Int. J. Automot. Technol. 2013, 14, 459-469.

11. He, Y.; Chowdhury, M.; Pisu, P.; Ma, Y. An energy optimization strategy for power-split drive train plug-in hybrid electric vehicles. Transp. Res. C 2012, 22, 29-41.

12. Zhang, C.; Vahidi, A. Route preview in energy management of plug-in hybrid vehicles. IEEE Trans. Control Syst. Technol. 2012, 20, 546-553.

13. Zhou, F.; Li, S.Q.; Hou, X. Development method of simulation and test system for vehicle body CAN bus based on CANoe. In Proceedings of the World Congress on Intelligent Control and Automation (WCICA), Chongqing, China, 25-27 June 2008; pp. 7515-7519.

14. Yao, L.L.; Wu, J.; Wang, Y.; Liu, C.F. Research on vehicle integrated control algorithm based on MATLAB and CANoe co-simulation. In Proceedings of the IEEE Transportation Electrification Asia-Pacific (ITEC), Beijing, China, 31 August-3 September 2014; pp. 1-5.

15. Tang, H.L. Plug-in Hybrid Bus Control Strategy Optimization and System Simulation; Beijing Institute of Technology: Beijing, China, 2014. (In Chinese)

(C) 2015 by the authors; licensee MDPI, Basel, Switzerland. This article is an open access article distributed under the terms and conditions of the Creative Commons Attribution license (http://creativecommons.org/licenses/by/4.0/). 